\title{
A Dynamic Study of Some Biological Active Compounds in the Sea-Buckthorn (Hippophae rhamnoides.L) Berries
}

\author{
Bayaraa Sukhbaatar, Battulga Borbaatar, Bayanmunkh Altangerel, Lkhagva Luvsannyam. and Khurelbaatar \\ Luvsan
}

The Department of Pharmaceutical chemistry, Drug Research Institute, Ulaanbaatar 11000, Mongolia

\begin{abstract}
In Mongolia, the sea buckthorn is a nontraditional fruit crop. It has been being planted since 2000 in the Botanical garden of Medicinal plants of Monos group, Mongolia. The purpose of this study was to determine how to change biological active compounds in the Sea-buckthorn berries that depending on harvesting season and to describe which harvesting period is efficient to use. In 2013-2014, fruit samples were prepared from our botanical garden such as: Chuiskaya, Maslichnaya, Vitaminnaya, Oranjivaya, Obilniya and Red cultivars on their chemical composition depended from harvesting season. The chemical compositions of fruit were investigated from 19th August to 20th January. We determined total oil, organic acid contents, $\beta$-carotenoid, ascorbic acid, total phenolic content and polysaccharide. The chemical contents were analyzed with the Folin-Ciocalteau assay, colorimetric assay, volume metric analysis method and spectrophotometric method. During the harvesting period, the chemical compositions of samples such as total oil content and polysaccharide content were increased and the contents of organic acid, beta carotenoid and ascorbic acid were decreased. From our study, we concluded that fruit biological active compounds depend from harvest time and it could be used to choose production of seabuckthorn product types.
\end{abstract}

Key words: Chuiskaya, Maslichnaya, Vitaminnaya, Orangevaya, Obilnaya, harvesting season.

\section{Introduction}

In recent years, due to sea-buckthorn fruit cultivation in our country to promote the health of national food brands and products based upon market penetration. However, the current condition of the sea buckthorn cultivation increased significantly wild sea natural resource degradation, cultivation of local varieties derived slowed down markedly in the past, from the outside before there are varieties cultivated image as a mixture of common buckthorn. At the international level, the situation is reversed sea buckthorn uniform standardization of raw materials, product ingredients, impacts on human health act pharmacology and clinical research, and the use of proper study of product requirements [1].

Currently, several standards related to raw materials our country are being investigated for the production of biologically active products, but direct application

Corresponding autor: Bayaraa Sukhbaatar, M.Sc, research fields: Pharmaceutical chemistry. of these standards are lacking, so it should be upgraded. Sea buckthorn berries contain a set of biologically active compounds, depending on how the season is changing harvesting products for both raw materials and thus the product can be used as a key measure to standardize it. The aims of the present study were to determine a dynamic study for biological active compounds in the sea buckthorn cultivars. This study will report experimental results on the characteristics of chemical compositions of its harvesting periods which could be select to further sea buckthorn products.

\section{Materials and Methods}

In this study, the botanical garden of medicinal plantd for "Monos" Group cultivated Red friut Maslichnaya, Vitaminnaya, Chuiskaya, Obilinaya and Oranjyevaya selected varieties of seabuckthorn berries From 19 August, 2013 to 20 January, 2014 sampled 10 times for each varieties. 
The total phenolic contents of dry medicinal plants were determined with the Folin-Ciocalteau assay by spectrophotometer. We measured at $750 \mathrm{~nm}$ UV-Visible spectrophotometer absorbance of samples, then compared it with standard solution of Gallic acid [2].

The total polysaccharide content was determined by spectrophotometer. We measured at $488 \mathrm{~nm}$ absorbance of samples, then compared it with standard solution of $\beta$-D Glucose [3].

Samples ascorbic acid, total organic acids, and total oil meet the general requirements for tablets by Mongolian National First Pharmacopeia, $\beta$ - carotene, Polyphenol compound, and total polysaccharide content was determined by spectrophotometric method [4].

\section{Results}

The research work was done at the department of pharmaceutical chemistry in Drug Research Institute and Botanical garden of the "Monos" Group. The biological active compounds in sea-buckthorn berries are shown on Table 1 depending on how season was changing and shown in Figs. 1-4.

As can be seen from Fig. 1, content of Ascorbic acid was being trended to constantly decrease during August to January. The red berry sort's total ascorbic acid content was the lowest concentration in end of the August, the Oranjevaya, and Chuiskaya sort's total ascorbic acid content was highest concentration on December and January. The berries' simple organic acids and water-soluble vitamins/lemon, tartaric acid, malic acids, synthesis of vitamin B1, B2, B3, B5, B6 depended on the total sugar and ascorbic acid content, maybe their accumulation and decomposition of changed in temperature. Therefore, in our opinion berries organic acids and vitamin concentration slowly decreased from August during the total research time. It is necessary to determine sugar content in berries. The concentration of organic acid is shown in Fig. 2.
Organic acids are known varieties of the highest concentration at the end of August. Drift is expected to decrease the concentration of the cold season. But the 1 st sort's berries collected total organic acid concentration increased up to November 20 to January 20. Maybe this sort contains much amount of sugar other sorts that sugar decomposed on November 20 to January 20.

$\beta$-carotene content, depending by the time are shown in Fig. 3.

All of sort's berries $\beta$-carotene content was increased in maturation period. However next month $\beta$-carotene content was slowly resolution. In our view, the $\beta$-carotene is fat-soluble, so maybe this combination changed depending on the amount of fat content. Amounts of oil contained in the fruits are shown in Fig. 4.

As can be seen from Fig. 4, the total amount of oil varieties of 6.60-13.96 percent from 2nd weeks on August in berries harvest period but reduced to the minimum 6.9-11.87 percent from September 19. We determined total fats of Red fruit sort and Oranjevaya sort constantly increased till January 20. This two sort's total fat's concentration invariable during October 20. Accordingly, the berries contain high levels of oil on the cold season. So, if we used oil of sea-buckthorn for producing oil products when we choose cold season-November to January for preparing raw materials.

Fig. 4 shows the total amount of phenolic compounds which were being trended to constantly decrease during August to October. But some cultivars such as Maslichnaya, Obilinaya and Oranjevaya little bit have increased during end of October.

As can be seen, the polysaccharide contents were in range of $19.4 \mathrm{mg} / \mathrm{g}$ to $72.9 \mathrm{mg} / \mathrm{g}$ in selected sorts, in which Chuiskaya have the highest value of polysaccharide. Also the result showed that sea buckthorn contained high level of polysaccharide contents on October. The minimal polysaccharide content was found in winter season. 
Table 1 A changing of chemical constituents of sea-buckthorn berries that depending on harvesting period.

\begin{tabular}{|c|c|c|c|c|c|c|c|}
\hline № & ate & $\begin{array}{l}\text { Ascorbic acid, } \\
\mathrm{mg} / 100 \mathrm{~g}\end{array}$ & $\begin{array}{l}\beta \text {-carotene, } \\
\mathrm{mg} / 100 \mathrm{~g}\end{array}$ & $\begin{array}{l}\text { Total organic } \\
\text { acid, } \%\end{array}$ & Total oil, \% & $\begin{array}{l}\text { Polyphenols, } \\
\mathrm{mg} / \mathrm{g}\end{array}$ & $\begin{array}{l}\text { Polysaccharide, } \\
\mathrm{mg} / \mathrm{g}\end{array}$ \\
\hline \multirow{6}{*}{ Aug. 19, 2013} & 1 & $29.35 \pm 0.58$ & $3.83 \pm 0.08$ & $1.05 \pm 0.03$ & $6.60 \pm 0.26$ & $1.94 \pm 0.07$ & $34.93 \pm 1.40$ \\
\hline & 2 & $87.63 \pm 1.75$ & $1.87 \pm 0.05$ & $1.23 \pm 0.03$ & $11.90 \pm 0.45$ & $4.95 \pm 0.19$ & $23.23 \pm 0.93$ \\
\hline & 3 & $69.07 \pm 1.23$ & $1.64 \pm 0.05$ & $1.06 \pm 0.03$ & $10.08 \pm 0.40$ & $3.57 \pm 0.16$ & $36.73 \pm 1.45$ \\
\hline & 4 & $83.07 \pm 1.54$ & $2.49 \pm 0.07$ & $1.00 \pm 0.02$ & $14.50 \pm 0.48$ & $5.38 \pm 0.21$ & $52.31 \pm 2.01$ \\
\hline & 5 & $80.05 \pm 1.51$ & $1.78 \pm 0.04$ & $1.20 \pm 0.03$ & $11.37 \pm 0.45$ & $4.22 \pm 0.17$ & $31.97 \pm 1.40$ \\
\hline & 6 & $85.19 \pm 1.19$ & $1.73 \pm 0.04$ & $1.59 \pm 0.03$ & $13.96 \pm 0.50$ & $1.82 \pm 0.07$ & $25.76 \pm 1.01$ \\
\hline \multirow{6}{*}{ Aug. 29, 2013} & 1 & $18.69 \pm 0.80$ & $4.05 \pm 0.19$ & $1.12 \pm 0.03$ & $6.76 \pm 0.25$ & $2.35 \pm 0.09$ & $36.54 \pm 1.44$ \\
\hline & 2 & $73.38 \pm 3.54$ & $2.19 \pm 0.09$ & $1.05 \pm 0.03$ & $8.91 \pm 0.30$ & $4.92 \pm 0.18$ & $25.52 \pm 0.95$ \\
\hline & 3 & $47.70 \pm 2.25$ & $1.51 \pm 0.07$ & $1.21 \pm 0.03$ & $9.60 \pm 0.35$ & $3.82 \pm 0.17$ & $40.53 \pm 1.62$ \\
\hline & 4 & $47.30 \pm 2.10$ & $2.66 \pm 0.12$ & $0.96 \pm 0.02$ & $9.54 \pm 0.35$ & $5.32 \pm 0.20$ & $62.31 \pm 2.40$ \\
\hline & 5 & $47.02 \pm 1.85$ & $2.05 \pm 0.10$ & $0.87 \pm 0.02$ & $7.40 \pm 0.25$ & $4.02 \pm 0.16$ & $36.85 \pm 1.50$ \\
\hline & 6 & $74.74 \pm 3.50$ & $1.97 \pm 0.09$ & $1.33 \pm 0.03$ & $8.49 \pm 0.24$ & $2.08 \pm 0.08$ & $29.71 \pm 1.18$ \\
\hline \multirow{6}{*}{ Sep. 09, 2013} & 1 & $15.17 \pm 0.65$ & $3.34 \pm 0.15$ & $1.03 \pm 0.02$ & $6.87 \pm 0.25$ & $2.16 \pm 0.08$ & $39.50 \pm 1.62$ \\
\hline & 2 & $71.50 \pm 3.12$ & $1.57 \pm 0.07$ & $0.97 \pm 0.02$ & $6.80 \pm 0.25$ & $4.90 \pm 0.18$ & $28.82 \pm 1.12$ \\
\hline & 3 & $50.03 \pm 2.56$ & $2.12 \pm 0.10$ & $1.12 \pm 0.03$ & $8.83 \pm 0.25$ & $3.41 \pm 0.15$ & $42.63 \pm 1.62$ \\
\hline & 4 & $53.49 \pm 5.75$ & $1.57 \pm 0.07$ & $0.85 \pm 0.02$ & $10.53 \pm 0.35$ & $5.08 \pm 0.18$ & $66.27 \pm 2.50$ \\
\hline & 5 & $46.03 \pm 2.01$ & $1.89 \pm 0.08$ & $1.29 \pm 0.03$ & $8.77 \pm 0.28$ & $3.97 \pm 0.15$ & $37.82 \pm 1.58$ \\
\hline & 6 & $74.81 \pm 5.46$ & $2.13 \pm 0.11$ & $1.19 \pm 0.03$ & $9.30 \pm 0.36$ & $2.35 \pm 0.08$ & $31.77 \pm 1.20$ \\
\hline \multirow{6}{*}{ Sept. 19, 2013} & 1 & $24.51 \pm 0.73$ & $4.24 \pm 0.08$ & $0.61 \pm 0.02$ & $9.67 \pm 0.27$ & $1.94 \pm 0.06$ & $40.52 \pm 1.50$ \\
\hline & 2 & $70.50 \pm 2.82$ & $1.94 \pm 0.04$ & $0.78 \pm 0.02$ & $10.45 \pm 0.32$ & $3.58 \pm 0.14$ & $29.87 \pm 1.21$ \\
\hline & 3 & $46.54 \pm 0.94$ & $2.17 \pm 0.06$ & $0.82 \pm 0.02$ & $8.46 \pm 0.24$ & $3.16 \pm 0.14$ & $45.84 \pm 1.43$ \\
\hline & 4 & $46.48 \pm 0.87$ & $2.53 \pm 0.05$ & $0.56 \pm 0.01$ & $8.56 \pm 0.26$ & $4.15 \pm 0.16$ & $69.15 \pm 2.82$ \\
\hline & 5 & $52.86 \pm 0.75$ & $2.14 \pm 0.03$ & $0.67 \pm 0.02$ & $11.87 \pm 0.25$ & $3.05 \pm 0.12$ & $40.61 \pm 1.65$ \\
\hline & 6 & - & - & - & $6.89 \pm 0.20$ & $2.16 \pm 0.08$ & $35.71 \pm 1.35$ \\
\hline \multirow{6}{*}{ Sept. 29, 2013} & 1 & $21.47 \pm 0.75$ & $4.16 \pm 0.08$ & $0.84 \pm 0.02$ & $14.86 \pm 0.40$ & $1.24 \pm 0.05$ & $45.84 \pm 1.74$ \\
\hline & 2 & $68.50 \pm 2.75$ & $2.34 \pm 0.05$ & $0.82 \pm 0.02$ & $13.00 \pm 0.38$ & $2.83 \pm 0.11$ & $35.94 \pm 1.36$ \\
\hline & 3 & $45.84 \pm 1.01$ & $1.82 \pm 0.03$ & $0.67 \pm 0.02$ & $11.64 \pm 0.35$ & $2.64 \pm 0.10$ & $53.68 \pm 2.14$ \\
\hline & 4 & $41.24 \pm 1.24$ & $2.37 \pm 0.04$ & $0.50 \pm 0.02$ & $10.50 \pm 0.35$ & $3.48 \pm 0.13$ & $69.15 \pm 2.81$ \\
\hline & 5 & $50.16 \pm 1.38$ & $2.08 \pm 0.05$ & $0.70 \pm 0.02$ & $12.66 \pm 0.36$ & $2.57 \pm 0.10$ & $45.61 \pm 1.82$ \\
\hline & 6 & - & - & - & - & $3.17 \pm 0.12$ & $36.71 \pm 1.52$ \\
\hline \multirow{6}{*}{ Oct. 18, 2013} & 1 & $16.83 \pm 1.30$ & $3.07 \pm 0.16$ & $0.62 \pm 0.02$ & $15.41 \pm 0.46$ & $1.48 \pm 0.05$ & $48.72 \pm 1.95$ \\
\hline & 2 & $67.70 \pm 3.35$ & $2.29 \pm 0.11$ & $0.88 \pm 0.02$ & $14.74 \pm 0.42$ & $2.65 \pm 0.12$ & $38.91 \pm 1.48$ \\
\hline & 3 & $44.83 \pm 2.25$ & $1.51 \pm 0.06$ & $0.61 \pm 0.02$ & $13.7 \pm 0.40$ & $2.27 \pm 0.09$ & $61.60 \pm 2.40$ \\
\hline & 4 & $31.92 \pm 1.52$ & $1.24 \pm 0.05$ & $0.52 \pm 0.01$ & $12.15 \pm 0.37$ & $2.86 \pm 0.13$ & $62.11 \pm 2.45$ \\
\hline & 5 & $49.75 \pm 2.45$ & $1.83 \pm 0.08$ & $0.70 \pm 0.02$ & $16.75 \pm 0.42$ & $2.73 \pm 0.12$ & $48.81 \pm 2.08$ \\
\hline & 6 & $40.63 \pm 2.02$ & $3.03 \pm 0.14$ & $0.86 \pm 0.02$ & $10.40 \pm 0.21$ & $2.28 \pm 0.09$ & $36.82 \pm 1.44$ \\
\hline \multirow{6}{*}{ Oct. 30, 2013} & 1 & $10.21 \pm 0.51$ & $3.38 \pm 0.11$ & $0.50 \pm 0.01$ & $15.61 \pm 0.62$ & $1.72 \pm 0.06$ & $57.99 \pm 2.25$ \\
\hline & 2 & $55.35 \pm 2.21$ & $2.42 \pm 0.07$ & $1.08 \pm 0.03$ & $15.12 \pm 0.45$ & $2.21 \pm 0.08$ & $42.31 \pm 1.68$ \\
\hline & 3 & $35.80 \pm 0.81$ & $2.03 \pm 0.04$ & $0.87 \pm 0.03$ & $14.25 \pm 0.50$ & $4.21 \pm 0.17$ & $72.99 \pm 2.81$ \\
\hline & 4 & $34.87 \pm 0.70$ & $1.75 \pm 0.06$ & $0.77 \pm 0.02$ & $13.05 \pm 0.42$ & $2.39 \pm 0.10$ & $65.62 \pm 2.64$ \\
\hline & 5 & $52.60 \pm 2.60$ & $1.88 \pm 0.07$ & $0.71 \pm 0.02$ & $18.08 \pm 0.41$ & $2.99 \pm 0.12$ & $59.99 \pm 2.41$ \\
\hline & 6 & $43.64 \pm 1.60$ & $2.75 \pm 0.07$ & $0.81 \pm 0.02$ & $10.58 \pm 0.35$ & $3.01 \pm 0.12$ & $41.00 \pm 1.61$ \\
\hline
\end{tabular}


(table 1 continued)

\begin{tabular}{llllllll}
\hline № & Date & $\begin{array}{l}\text { Ascorbic acid, } \\
\mathrm{mg} / 100 \mathrm{~g}\end{array}$ & $\begin{array}{l}\beta \text {-carotene, } \\
\mathrm{mg} / 100 \mathrm{~g}\end{array}$ & $\begin{array}{l}\text { Total organic } \\
\text { acid, } \%\end{array}$ & Total oil, $\%$ & $\begin{array}{l}\text { Polyphenols, } \\
\mathrm{mg} / \mathrm{g}\end{array}$ & $\begin{array}{l}\text { Polysaccharide, } \\
\mathrm{mg} / \mathrm{g}\end{array}$ \\
\hline & 1 & $9.24 \pm 0.27$ & $3.18 \pm 0.08$ & $0.61 \pm 0.02$ & $14.87 \pm 0.35$ & $1.54 \pm 0.06$ & $45.93 \pm 1.84$ \\
& 2 & $49.22 \pm 1.47$ & $2.33 \pm 0.07$ & $0.68 \pm 0.02$ & $14.82 \pm 0.31$ & $2.25 \pm 0.09$ & $38.01 \pm 1.50$ \\
Nov. 20, 2013 & 3 & $27.58 \pm 1.02$ & $2.09 \pm 0.04$ & $0.72 \pm 0.02$ & $14.18 \pm 0.30$ & $2.08 \pm 0.08$ & $50.62 \pm 1.98$ \\
& 4 & $29.77 \pm 1.00$ & $1.83 \pm 0.06$ & $0.80 \pm 0.02$ & $12.86 \pm 0.25$ & $2.32 \pm 0.08$ & $57.63 \pm 2.36$ \\
& 5 & $45.12 \pm 1.65$ & $1.81 \pm 0.07$ & $0.57 \pm 0.01$ & $17.76 \pm 0.26$ & $2.84 \pm 0.12$ & $39.67 \pm 1.58$ \\
& 6 & $42.82 \pm 1.24$ & $2.81 \pm 0.07$ & $0.66 \pm 0.02$ & $9.75 \pm 0.20$ & $1.83 \pm 0.07$ & $38.15 \pm 1.52$ \\
\hline & 1 & $9.08 \pm 0.25$ & $3.31 \pm 0.08$ & $0.70 \pm 0.02$ & $15.28 \pm 0.30$ & $1.18 \pm 0.05$ & $38.96 \pm 1.50$ \\
Dec. 20, 2013 & 2 & $42.54 \pm 1.54$ & $2.42 \pm 0.07$ & $0.72 \pm 0.02$ & $15.64 \pm 0.30$ & $2.20 \pm 0.09$ & $40.06 \pm 1.55$ \\
& 3 & $22.43 \pm 0.62$ & $2.13 \pm 0.04$ & $0.94 \pm 0.03$ & $14.96 \pm 0.28$ & $1.83 \pm 0.06$ & $32.68 \pm 1.15$ \\
& 4 & $25.13 \pm 0.65$ & $1.72 \pm 0.06$ & $0.97 \pm 0.03$ & $13.17 \pm 0.28$ & $2.01 \pm 0.07$ & $49.81 \pm 1.86$ \\
& 5 & $42.52 \pm 1.35$ & $1.83 \pm 0.07$ & $0.87 \pm 0.02$ & $18.53 \pm 0.42$ & $2.15 \pm 0.07$ & $24.18 \pm 0.84$ \\
& 6 & $37.21 \pm 1.18$ & $2.70 \pm 0.07$ & $0.77 \pm 0.02$ & $10.92 \pm 0.23$ & $1.54 \pm 0.06$ & $44.52 \pm 1.74$ \\
\hline & 1 & $8.52 \pm 0.25$ & $3.18 \pm 0.08$ & $1.65 \pm 0.02$ & $15.19 \pm 0.40$ & $1.08 \pm 0.05$ & $35.93 \pm 1.34$ \\
Jan. 20, 2014 & 2 & $38.21 \pm 0.09$ & $2.12 \pm 0.07$ & $1.05 \pm 0.02$ & $15.35 \pm 0.38$ & $1.88 \pm 0.07$ & $37.01 \pm 1.42$ \\
& 3 & $18.09 \pm 0.50$ & $2.01 \pm 0.04$ & $0.87 \pm 0.02$ & $14.87 \pm 0.32$ & $1.67 \pm 0.07$ & $30.68 \pm 1.18$ \\
& 4 & $21.77 \pm 0.61$ & $1.45 \pm 0.06$ & $0.92 \pm 0.02$ & $13.52 \pm 0.30$ & $1.86 \pm 0.08$ & $47.81 \pm 1.88$ \\
5 & $32.54 \pm 0.85$ & $1.37 \pm 0.07$ & $0.78 \pm 0.02$ & $17.95 \pm 0.35$ & $1.95 \pm 0.08$ & $19.44 \pm 0.78$ \\
& 6 & $35.14 \pm 0.87$ & $2.42 \pm 0.07$ & $0.89 \pm 0.02$ & $11.05 \pm 0.28$ & $1.48 \pm 0.05$ & $41.49 \pm 1.67$ \\
\hline
\end{tabular}

1-Red friut, 2-Chuiskaya, 3-Maslichnaya, 4-Vitaminnaya, 5-Obilnaya, 6-Oranjevaya $n=5, p \geq 0.05, \pm \mathrm{SD}$.

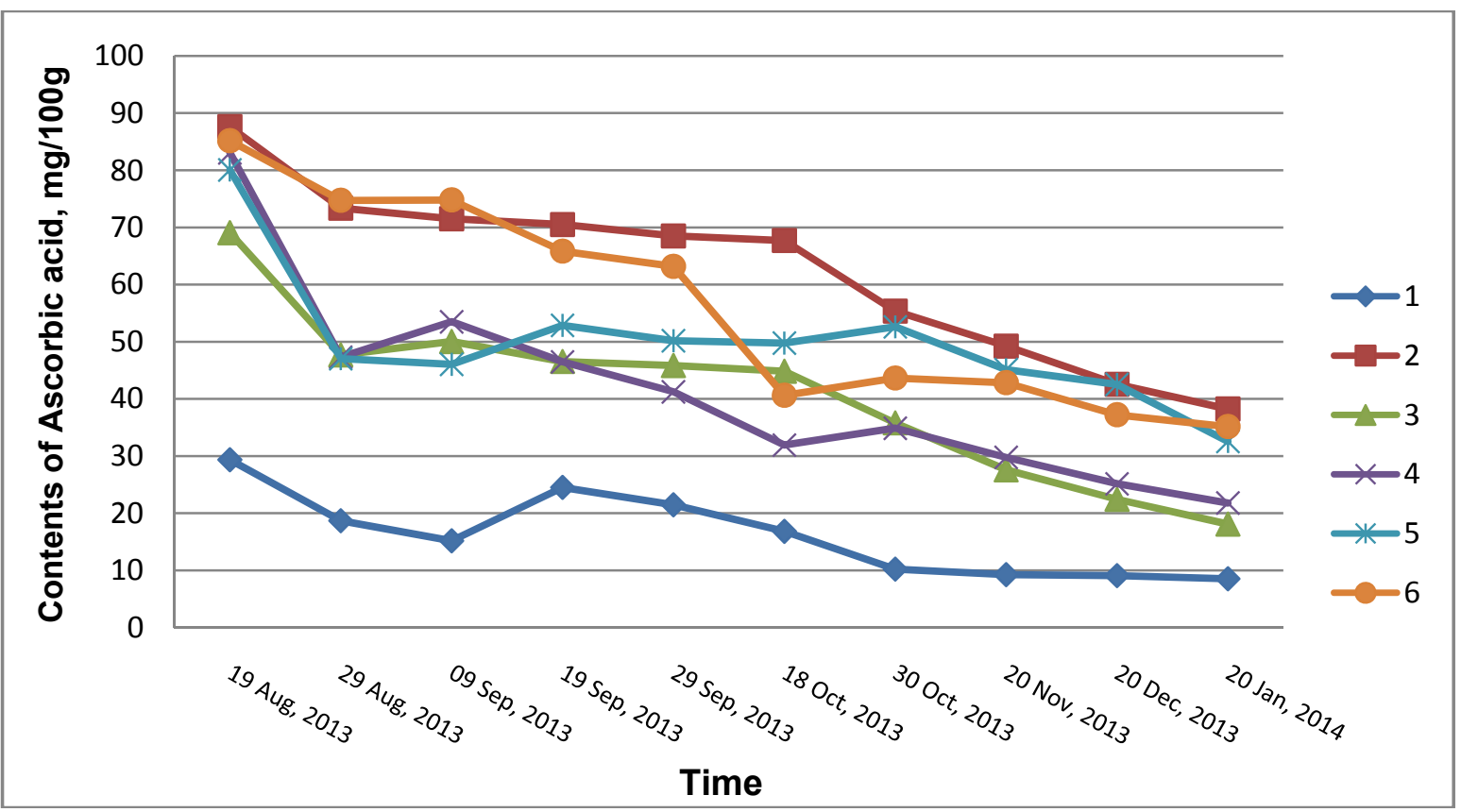

Fig. 1 Diagram for contents of Ascorbic acid are depended by time. 


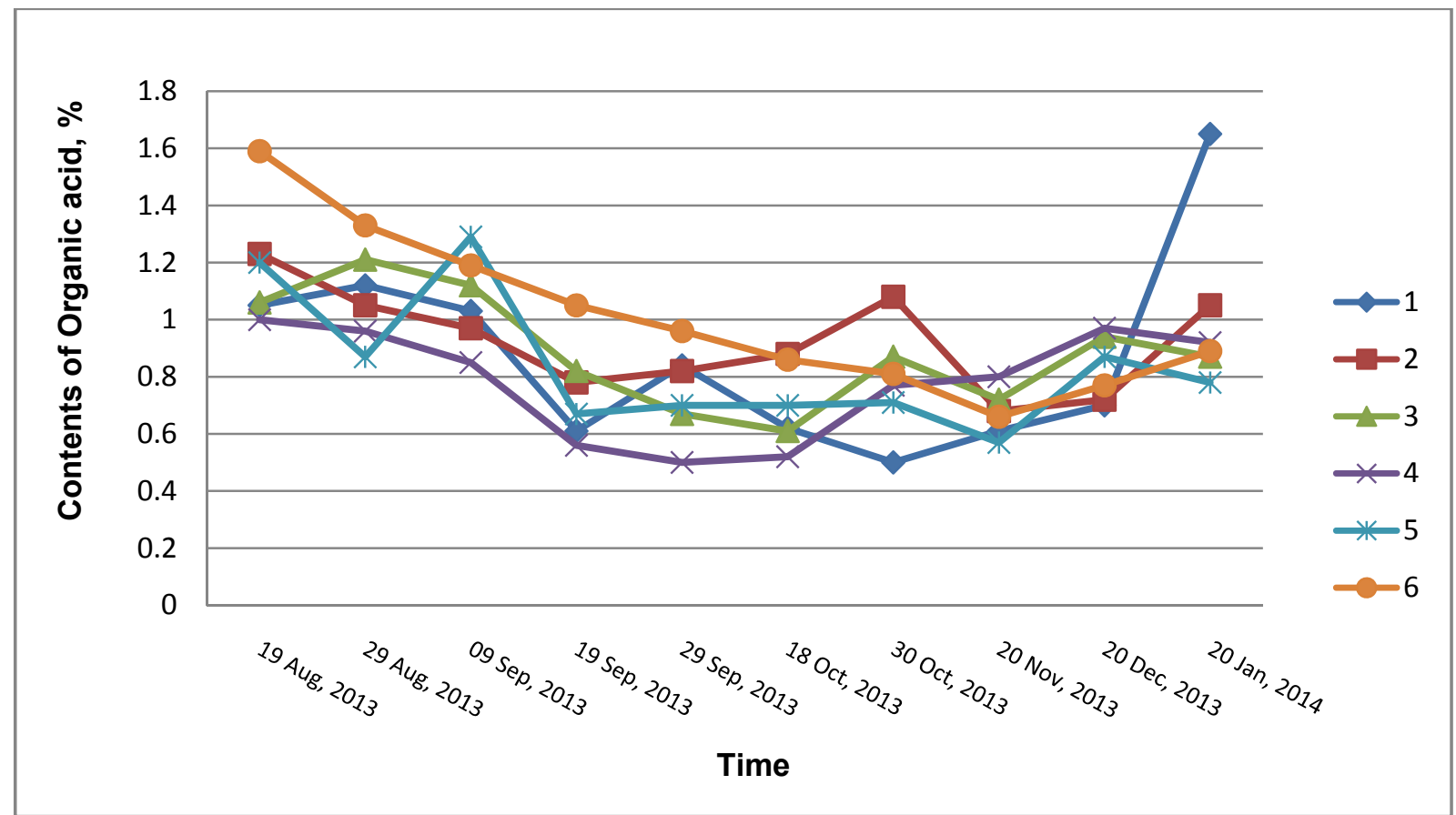

Fig. 2 Diagram for contents of Organic acid are depended by time.

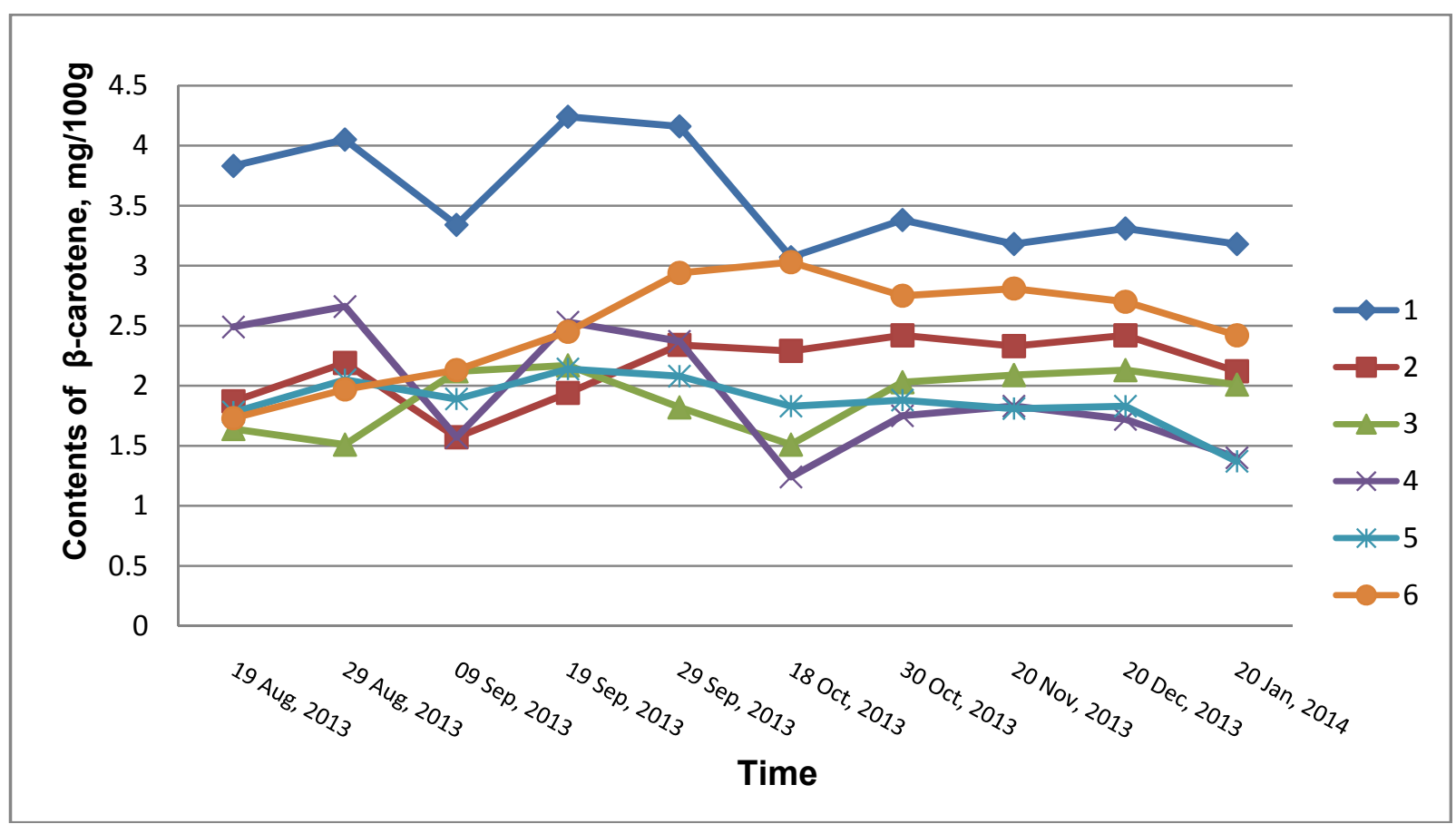

Fig. 3 Diagram for contents of $\beta$-carotene are depended by time. 


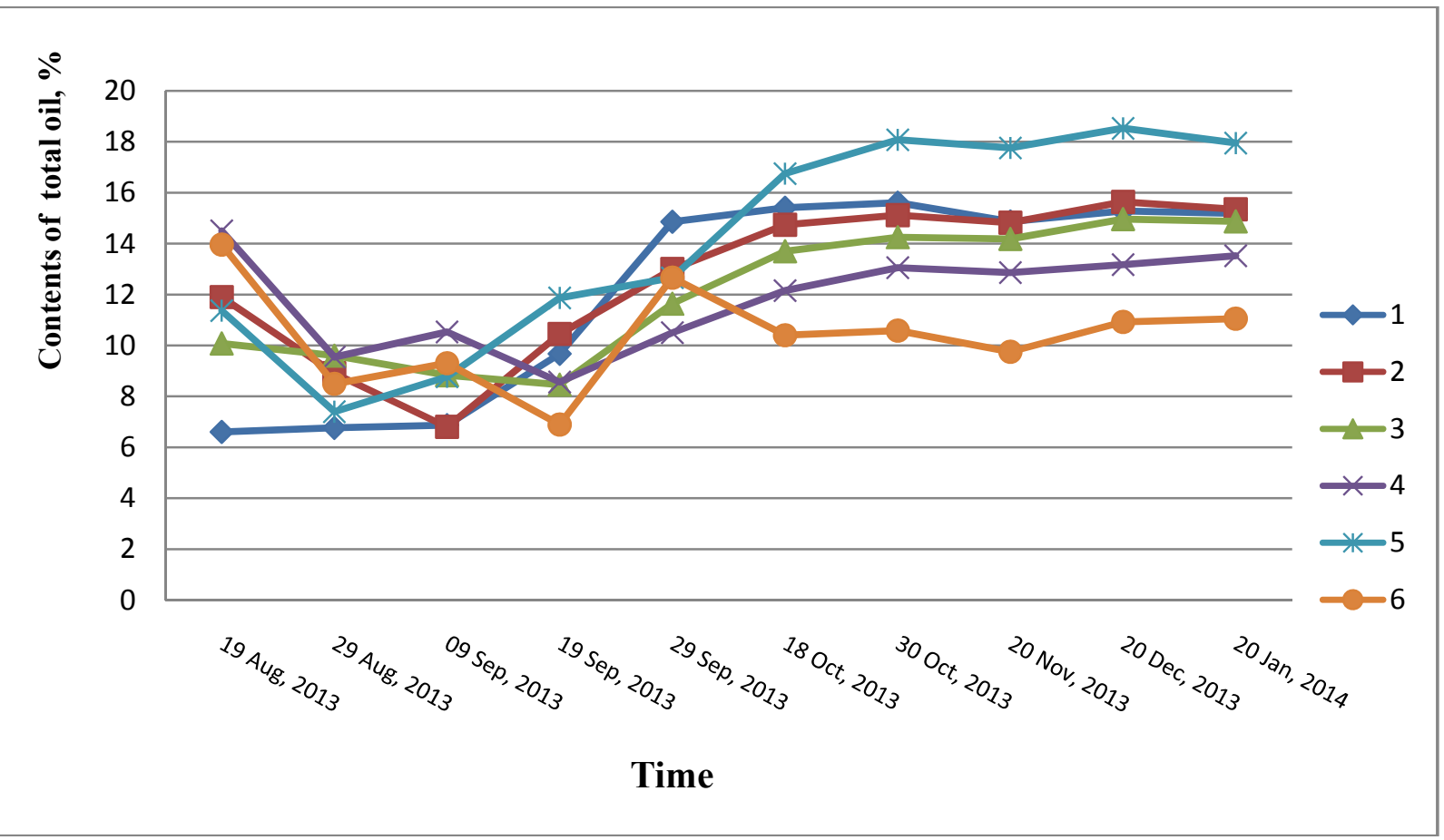

Fig. 4 Diagram for contents of total oil are depended by time.

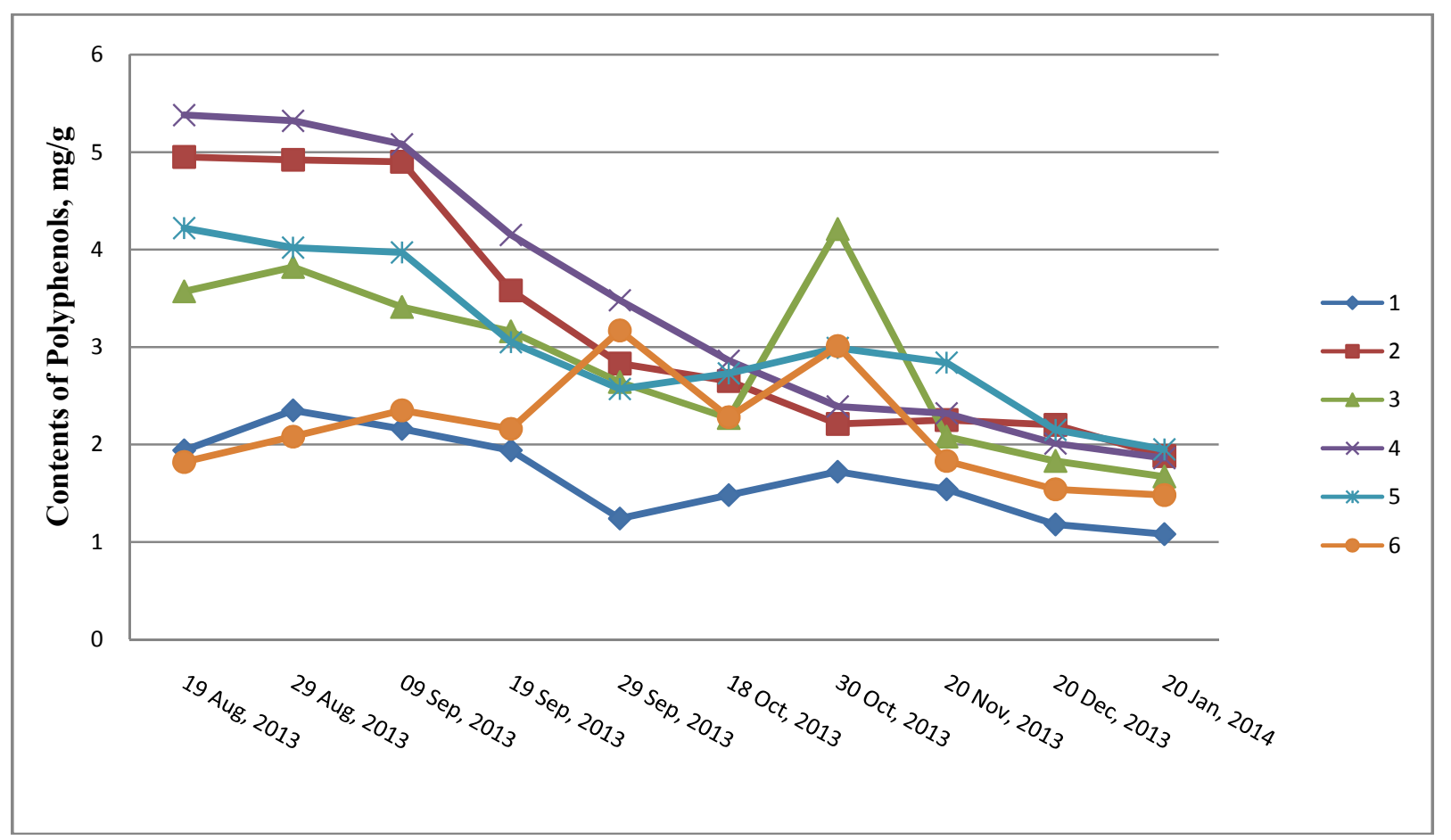

Fig. 5 Diagram for contents of total phenolic compounds are depended by time. 


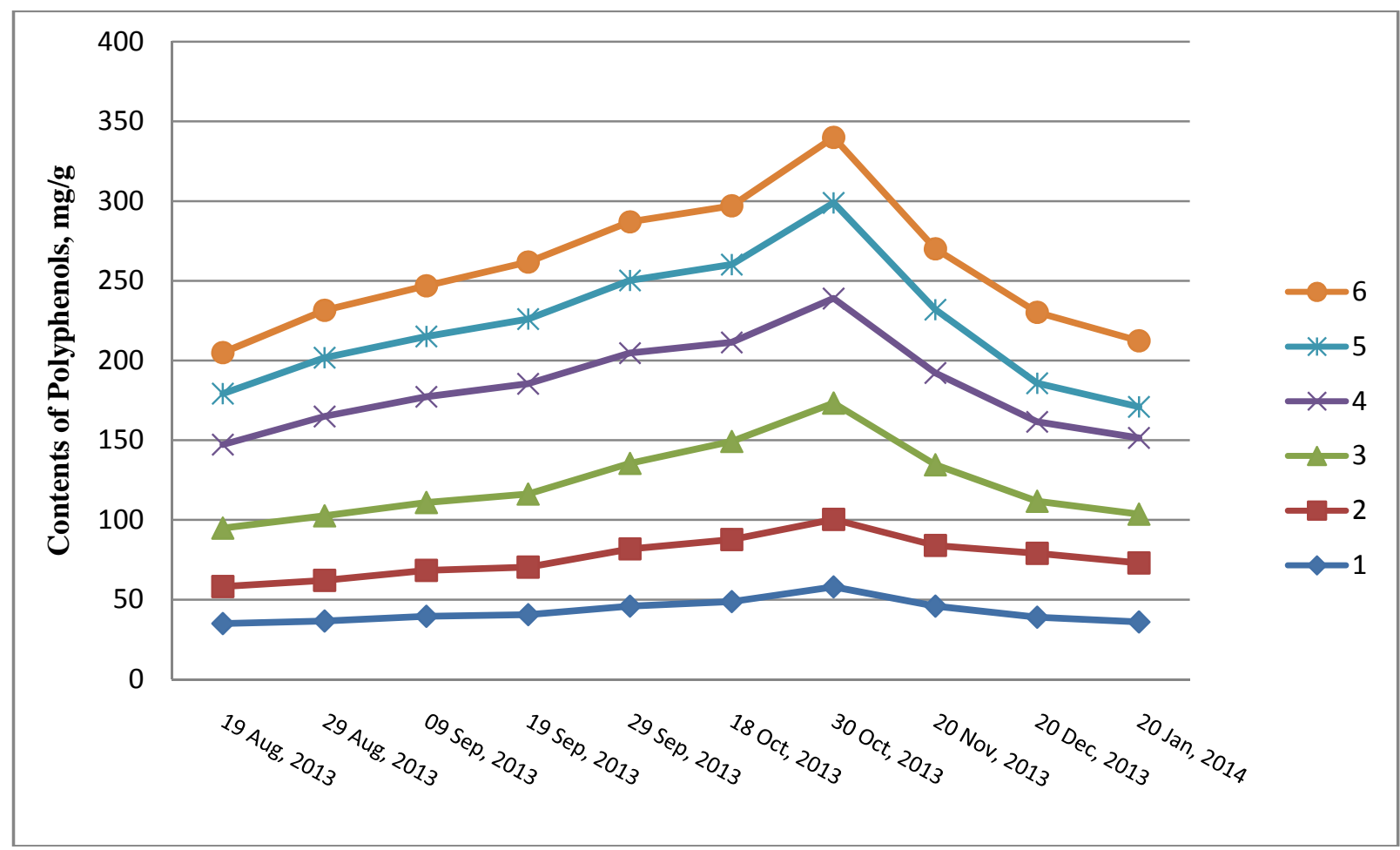

Fig. 6 Diagram for contents of polysaccharide compounds are depended by time.

\section{Discussion}

The ascorbic acid highest concentration of 29.35-83.07 $\mathrm{mg} \%$ at the end of August is to met Chinese researcher. In Russian border with Mongolia region, growing varieties total ascorbic acid content is 40-310 mg\%.

The berries fat content is $6.60-13.96 \%$, at the end of the August is meet the Russian researcher [5] determined of the Altai nearest growing sea buckthorn oil content.

Most of the researchers studied carotenoids in the sea-bucthorn, depending on the amount of oil concentration [6-8]. In our study, carotenoids content depending on the amount of oil was met.

\section{Conclusions}

The results of study sea buckthorn's all sort berries total ascorbic acid 29-85 mg\%, beta-carotene 1.78-3.8 mg, organic acids $1.0-1.59 \%$ of the total oil $6.60-13.96 \%$ concentrations at the end of August. We determine all sort berries' biological active substance changed, ascorbic acid 8.52-35.4 mg\%, beta-carotene 1.37-2.42 mg, organic acids $0.78-1.05 \%$ of the total fat $11.05-17.95 \%$ concentrations at the January 20. Berries' total fat concentrations constantly increased in August to January but other three kind of biological compounds such as ascorbic acid, beta-carotene, organic acid amounts constantly decreased during in August to January. Our study demonstrates that there is a need to be established when it is the optimal harvesting time for preparing good quality raw materials from seabuckthorn for using it in the food and pharmaceutical industries.

\section{References}

[1] Dungerdorj, D., Munkhdelger, Ch., and Tsetsegmaa, S. 2011. Mongolian National Pharmacopeia, General requirements, 1: 564-84.

[2] Atanassova, M., Georgieva, S., and Ivancheva, K. 2011. "Total Phenolic and Total Flavonoids, Antioxidant Capacity and Biological Contaminants in Medicinal Herbs.” Journal of the University of Chemical Technology and Metallurgy 46 (1): 81-8.

[3] Manisha, B., and Anjoo, K. 2013. "Spectrophotometer Estimation of Total Polysaccharides in Kalachoepinnatum and Kalanchoecrenata." International Journal of Pharmacy and Pharmaceutical Sciences 2 (58): 40-1. 
[4] OAO "NIJPHARM" 2004. Pharmacopeia of Russian Federation, page 3, $\beta$-carotine.

[5] Zubarev, Y. A. 2009. Properties and Promising Ways of Sea Buckthorn Utilization at Altai. The Lisavenko Research Institute of Horticulture for Siberia Scientific Presentation.

[6] Lian, Y. S., Lu, S. G., Su, S. K., and Chen, X. L. 2000. "Biology and Chemistry of the Genus Hippophae." Dansu
Scientific and Technological Publishing House 3: 88-91.

[7] Yang, B. R., and Kallio, H. P. 2001. "Fatty Acid Composition of Lipids in Sea Buckthorn (Hippophae rhamnoides L.) Berries of Different Origins.” J. Agri. Food Chem 46: 1939-47.

[8] Alam, Z. 2004. "Chemical and Nutritional Constituents of Sea Buckthorn Juice.” Pakistan Journal of Nutrition 3 (2): 99-106. 